\title{
FRONTERAS DEL TRABAJO ASALARIADO Y NUEVAS FORMAS DE EMPLEO EN EUROPA: EL CASO DEL TRABAJO AUTÓNOMO YEL EMPRENDIZAJE ${ }^{1}$
}

\author{
Borders of employed work and new forms of employment in europe: the case of autonomous \\ work and learning
}

\begin{abstract}
Alberto Riesco-Sanz (Universidad Complutense de Madrid-Instituto TRANSOC)

Informações do artigo

Recebido em 05/08/2019

Aceito em 14/10/2019

doi>: https://doi.org/10.25247/2447-861X.2019.n248.p608-636
\end{abstract}

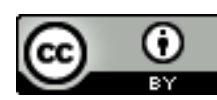

Esta obra está licenciada com uma Licença Creative Commons Atribuição 4.0 Internacional.

\section{Como ser citado (modelo ABNT)}

RIESCO-SANZ, Alberto. Fronteras del trabajo asalariado y nuevas formas de empleo en Europa: el caso del trabajo autónomo y el emprendizaje. Cadernos do CEAS: Revista Crítica de Humanidades. Salvador, n. 248, set./dez., p. 608-636, 2019. DOI: https://doi.org/10.25247/2447-861X.2019.n248.p608-636

\begin{abstract}
Resumen
El trabajo autónomo constituye una forma de empleo minoritaria en la Unión Europea. Identificado a menudo como signo de retraso económico, el trabajo autónomo ha alcanzado, sin embargo, recientemente en Europa un protagonismo en el debate público y en las políticas de empleo implementadas que no siempre se corresponde con su presencia real en el mercado de trabajo. A partir de un análisis de las dimensiones y transformaciones recientes del trabajo autónomo en Europa, este artículo trata de señalar algunas de sus señas de identidad características: desarrollo desigual dentro de la UE, vinculación a las políticas activas de empleo, mecanismo de flexibilización del mercado de trabajo, fenómeno concomitante a la denominada "uberización" de la economía, etc. Todos estos elementos pretenden servir como hilo conductor a partir del cual identificar y discutir otras transformaciones de más calado que podrían estar afectando al conjunto del empleo: proliferación de estatutos híbridos de empleo; extensión de las instituciones del trabajo asalariado $y$, al mismo tiempo, mutación de la relación salarial tradicional; desarrollo de modos de movilización y uso de las capacidades productivas que no pasan por el dispositivo "empresa", etc. Despojada de algunos presupuestos teóricos limitantes, la reflexión en torno al fenómeno del trabajo autónomo en Europa puede servir de base para una reflexión más ambiciosa que aporte elementos desde los cuáles pensar la propia transformación actual del salariado.

Palabras Clave: Trabajo autónomo. Transformación del salariado. Unión Europea.

Abstract

Self-employment represents a lesser and yet nonetheless widespread form of employment in the European Union. It has often been described as a sign of economic backwardness. However, self-employment has recently become an important topic in both public debate and employment policies. Starting out from an analysis of the extent of and recent changes in self-employment in Europe, this article describes some of the features and tensions which characterise this form of employment: dissimilar trends in different EU countries, increasingly linked to activation policies; potential mechanism for flexibilization of the labour market, and a phenomenon in accordance with the uberization of the economy, etc. The description of these aspects in this paper is proposed as a connecting thread for identifying and discussing other major changes and developments that could have an impact on employment: proliferation of forms of hybrid employment status; extension of wage employment institutions and, at the same time, changes in the traditional wage relationship; other forms of mobilisation and use of productive capacities that are not linked to the traditional 'company' form, etc. Given the current blurring of some formerly restrictive theoretical tenets, it becomes possible to expand this study of self-employment in Europe into a deeper and more far-reaching reflection on the radical nature of the changes currently affecting employment.

Keywords: Self-employment. Wage based-society transformation. European Union.
\end{abstract}

\footnotetext{
1 Las reflexiones recogidas en este artículo se han desarrollado dentro del proyecto de investigación "Fronteras del trabajo asalariado y nuevas formas de empleo. Trabajo autónomo y emprendizaje en la economía del conocimiento" (CSO2017-82292-R), financiado por el Ministerio de Economía, Industria y Competitividad y el Fondo Europeo de Desarrollo Regional (FEDER) dentro del Programa Estatal de Investigación, Desarrollo
} e Innovación orientada a los Retos de la Sociedad. Convocatoria 2017. 
En la historia contemporánea de Europa, la formación, movilización y uso de las capacidades productivas de la población han tendido a realizarse, de forma creciente aunque es cierto que no exclusiva, bajo alguna de las distintas modalidades de trabajo asalariado. La condicionalidad, el carácter fortuito y, en definitiva, la precariedad que la relación salarial imprime al encuentro entre poblaciones y actividades propició un largo $-y$ a menudo convulso- proceso de institucionalización y estabilización de las relaciones de trabajo. Un proceso necesario no sólo desde el punto de vista de la protección de las poblaciones afectadas, sino también como garantía para la consecución de los propios procesos productivos. Dicho proceso de institucionalización del empleo se tradujo -con intensidad y tiempos variables según los países - en un reconocimiento de derechos políticos, sociales y económicos para esas poblaciones, asícomo en la puesta en marcha de distintos mecanismos e instituciones destinadas a minimizar -a menudo vía su mutualización- los riesgos adscritos a las relaciones modernas de trabajo: riesgos básicamente derivados de la incapacitación sobrevenida para seguir participando en ellas en calidad de asalariado (co mo consecuencia de la enfermedad, la vejez, el desempleo, la obsolescencia de las competencias y saberes adquiridos, etc.).

El acceso a este conjunto novedoso de derechos y garantías no se extendió, sin embargo, de forma automática a toda la población potencialmente afectada, sino que se acompañó de una intensa actividad selectiva y clasificatoria por parte del Estado. De este modo, podríamos decir que la cristalización de una serie de derechos políticos, sociales y económicos en torno a un "estatuto del trabajo asalariado" se acompañó de un proceso de exclusión de tales garantías para una parte de las poblaciones trabajadoras europeas: aquellas, por ejemplo, que participaban de forma discontinua o irregular en el mercado de trabajo; que lo hacían bajo modalidades de empleo-porcuenta propia-o en sectores-como el servicio doméstico o el trabajo agrícola- que no se ajustaban a la delimitación de la condición salarial definida formalmente a partir de los principios jurídicos de ajenidad y subordinación.

Dicho proceso de exclusión debería ser, no obstante, matizado ya que, en la mayoría de los casos, conforme ha pasado el tiempo, hemos asistido en Europa a una cierta transferencia de derechos e instituciones adscritos originariamente al trabajo asalariado (o a una cierta composición del mismo) hacia colectivos y figuras laborales más amplios y heterogéneos que los contemplados inicialmente. Una extensión y ampliación significativa 
de las fronteras del "estatuto del trabajo asalariado" que desconfiguraría su "composición obrera" inicial para hacer de él una realidad más heterogénea en la que confluirán -con posiciones y derechos no siempre equiparados-figuras anteriormente contrapuestas: trabajadores industriales, campesinos, artistas, servicio doméstico, cuadros intermedios e incluso directivos, funcionarios, comerciales y profesiones liberales.

La fuerza expansiva con la que se muestra hoy el trabajo asalariado en las principales economías del mundo podría llevarnos a presuponer -equivocadamente- que estamos asistiendo a su homogenización. Nada más lejos de la realidad. Hoy asistimos en Europa a un incremento en la heterogeneidad y pluralidad de las modalidades de uso de las capacidades productivas de las poblaciones: ya sea en el seno mismo del trabajo asalariado formal (trabajo subcontratado, interino, a tiempo parcial, por horas...), o en su combinación variable con modalidades no asalariadas (trabajo por cuenta propia, trabajo voluntario, prácticas en empresas, trabajo no remunerado...) o directamente no declaradas. Modalidades no convencionales de uso del trabajo que conforman a menudo espacios y estatutos híbridos de empleo, muchas veces escasamente o mal formalizados, que interactúan cotidianamente pero se acoplan con dificultad a las instituciones y mecanismos del trabajo asalariado tradicional. Una pluralidad de modos y estatutos de empleo que se combinan con una geometría variable y abren no pocos desafíos desde el punto de vista de la coordinación y organización de los procesos productivos, pero también desde el punto de vista de la calidad y protección del empleo, al tiempo que apuntan a cambios importantes en la confo rmación de los regímenes de empleo conocidos en Europa. En este texto queremos prestar atención a una de estas modalidades no convencionales de utilización de la fuerza de trabajo en Europa: el trabajo autónomo. 


\section{El doble movimiento de transformación del trabajo autónomo en la Unión Europea²}

La Unión Europea (UE-28) contaba en 2015 con algo más de 35 millones de trabajadores por cuenta propia, en su mayoría -el 67\%- trabajadores autónomos sin asalariados. El trabajo formalmente no asalariado representaba asíun nada despreciable $16 \%$ de la población ocupada en la UE-28, si bien dicha presencia mostraba una distribución bastante desigual por países, tanto por encima como por debajo de la media europea (cf. Grafico 1). Esta distribución geográfica de los datosparece confirmar, en términos generales, la mayor persistencia del trabajo autónomo en los países del sur y este de Europa, con cifras que alcanzan el $22 \%$ y $19 \%$ de la población ocupada respectivamente (frente al $12,5 \%$ registrado en los países occidentales y escandinavos). Dicho en otras palabras, parece confirmar a simple vista la existencia de una cierta conexión entre (menor) desarrollo económico y (mayor) presencia de trabajo autónomo.

Gráfico 1 - Peso del trabajo no asalariado en el conjunto de la población

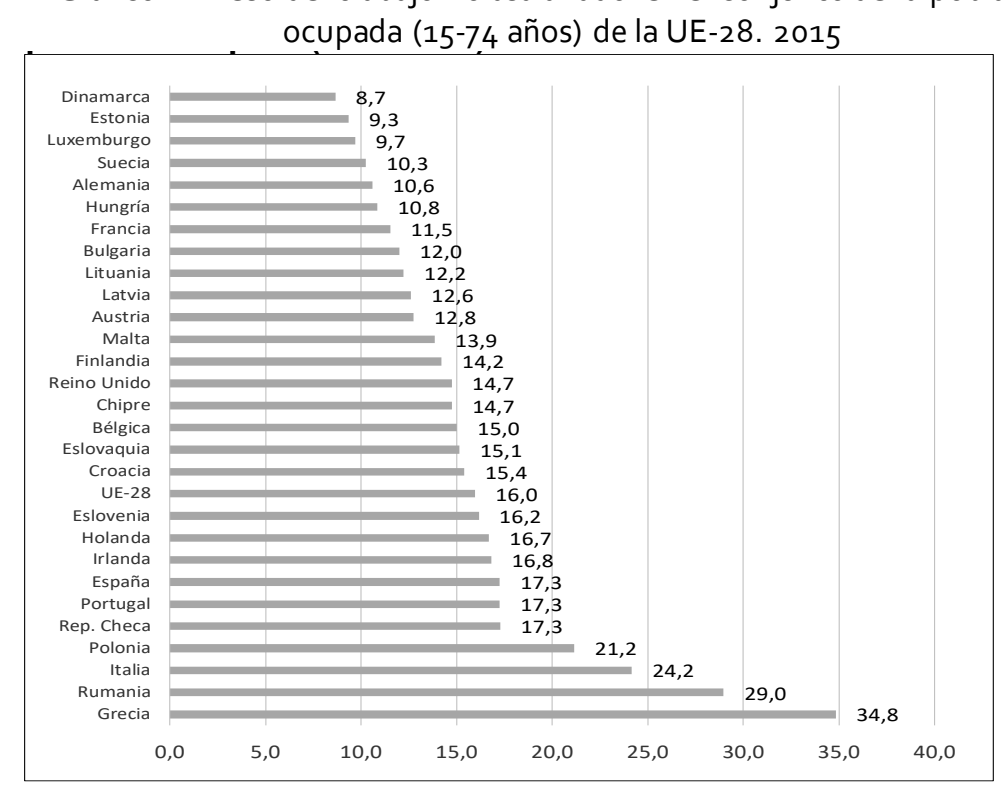

Fuente: Elaboración propia a partir de la European Union Labour Force Survey (Eurostat). Datos anuales, población 15-74 años.

\footnotetext{
2 Los datos empleados en este apartado proceden de la European Union Labour Force Survey de Eurostat (medias anuales, población 15-74 años). Salvo que se explicite lo contrario, utilizamos el término de "trabajo autónomo" de forma genérica, englobando en él a las diferentes modalidades de trabajo no asalariado existentes. Las estadísticas sobre trabajo autónomo se han basado, siempre que ha sido posible, en datos sobre "no asalariados". Los términos de norte, sur y este de Europa se emplean en este trabajo como categorías políticas más que geográficas.
} 
La dinámica del trabajo autónomo en Europa no responde, sin embargo, únicamente a esta lógica de niveles diferenciados de desarrollo. De hecho, aunque el trabajo autónomo siga siendo una forma de empleo con mayor presencia en los países del sur y este de Europa, cuando observamos el fenómeno con una cierta perspectiva temporal (cf. Gráficos 2, 3 y 4), podemos fácilmente constatarque son precisamente los países más ricos del continente los que han registrado un mayor crecimiento en el número de trabajadores autónomos durante las dos últimas décadas. En ese tiempo, los países del sur de Europa y las antiguas repúblicas socialistas integradas en la UE han conocido un importante descenso en el número de trabajadores autónomos, en el caso del sur de Europa especialmente desde el estallido de la crisis económica de 2008.

Gráfico 2 - Trabajadores no asalariados en los países escandinavos y Europa occidental (*), peso absoluto (eje izquierdo) y relativo (eje derecho), 1995-2015.

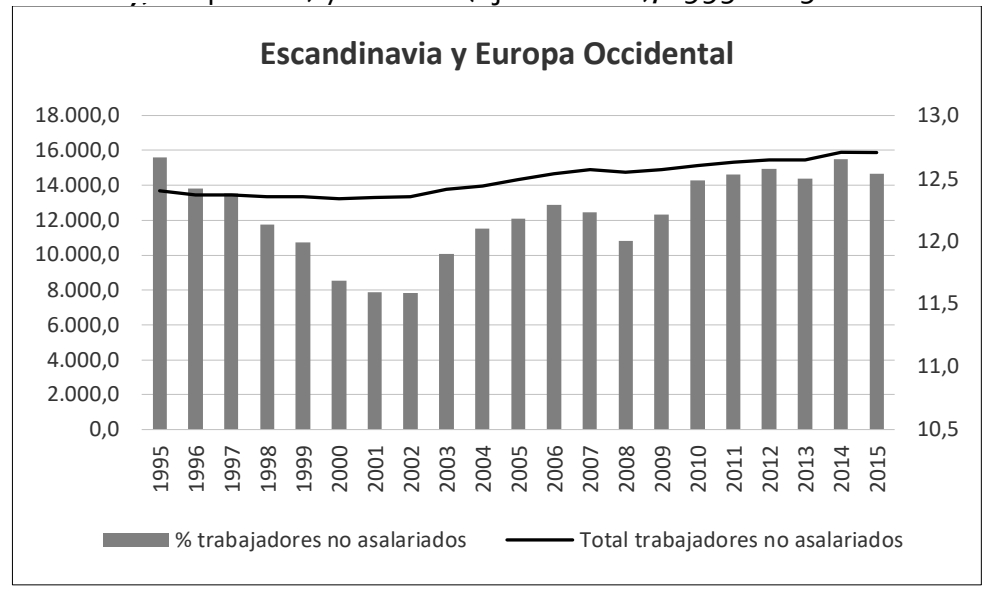

Fuente: Elaboración propia a partir de la European Union Labour Force Survey (Eurostat). Datos anuales, población 15-74 años.

(*) Alemania, Austria, Bélgica, Dinamarca, Finlandia, Francia, Holanda, Irlanda, Luxemburgo, Reino Unido y Suecia.

Gráfico 3 - Trabajadores no asalariados en los países del sur de Europa (*), peso absoluto (eje izquierdo) y relativo (eje derecho), 2000-2015.

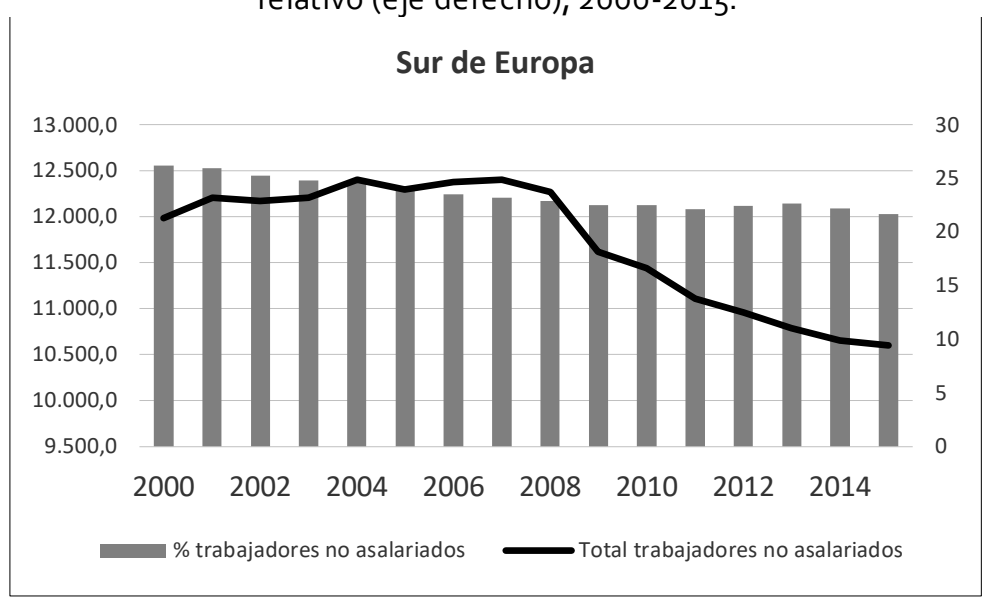

Fuente: Elaboración propia a partir de la European Union Labour Force Survey (Eurostat). Datos anuales, población 15-74 años.

(*) Chipre, España, Grecia, Italia, Malta y Portugal 
Así pues, los datos agregados podrían estar ofreciendo una imagen incompleta respecto a la evolución de este modo de empleo dentro de Europa. Por ejemplo, entre 2002 2015 la UE-28 registró un descenso en el número de trabajadores autónomos (749.000, una desaparición de 3,4 autónomos porcada 1000 personas ocupadas), que se reflejó igualmente en su peso en el conjunto del empleo (del 17,5\% al 16\%). En ese mismo periodo de tiempo, sin embargo, el sur de Europa perdió en torno a 1,4 millones de autónomos (28,2 autónomos porcada 1000 ocupados) y las antiguas repúblicas socialistas 1,7 millones de autónomos (38,8 autónomos porcada 1000 ocupados).

Gráfico 4 - Trabajadores no asalariados en los antiguos países socialistas de Europa (*), peso absoluto (eje izquierdo) y relativo (eje derecho), 2002-2015.

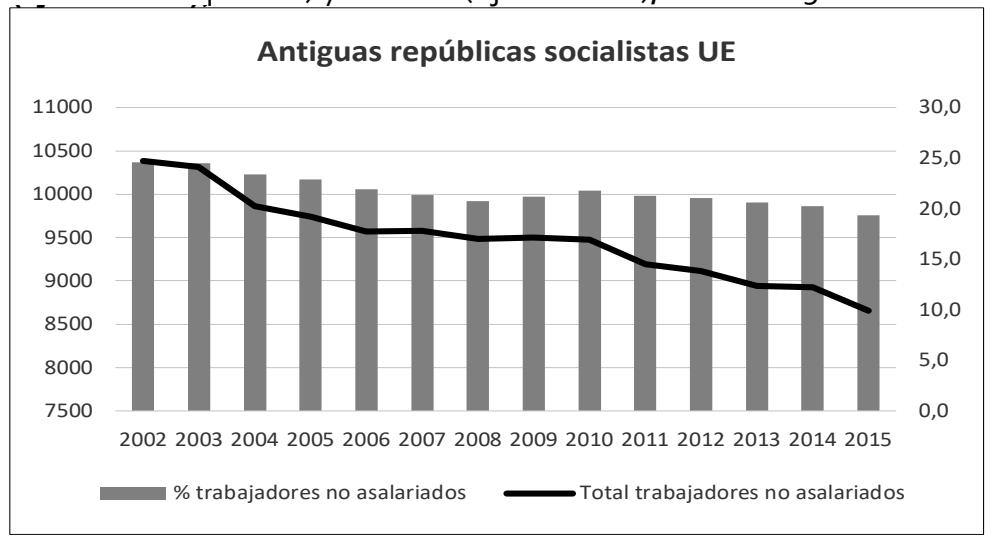

Fuente: Elaboración propia a partir de la European Union Labour Force Survey (Eurostat). Datos anuales, población 15-74 años.

(*) Bulgaria, Croacia, Eslovaquia, Eslovenia, Estonia, Hungría, Latvia, Lituania, Polonia, Rep. Checa y Rumania.

En claro contraste con esta situación, los países escandinavos y de Europa occidental registraron durante el mismo periodo un incremento de 2,6 millones de autónomos (21 autónomos porcada 1000 ocupados). En lo que se refiere a la dinámica geográfica del trabajo no asalariado en Europa nos encontramos pues con un doble movimiento: una clara expansión del mismo en los países escandinavos y occidentales (con una tasa de crecimiento entre 2000 y 2015 del $20 \%$, el doble de la registrada por el trabajo asalariado) y una contracción en el sur y este de Europa (con una pérdida del $11,5 \%$ y $16,7 \%$ respectivamente) (cf. Gráficos 5 y 6). ¿A qué se debería este comportamiento tan diferenciado del trabajo autónomo en unas y otras partes de Europa? Para tratarde responder a la pregunta tenemos que dar un pequeño rodeo. 
Gráfico 5 - Tasa de variación del número de ocupados en Europa según modo de empleo, 2000-2015.

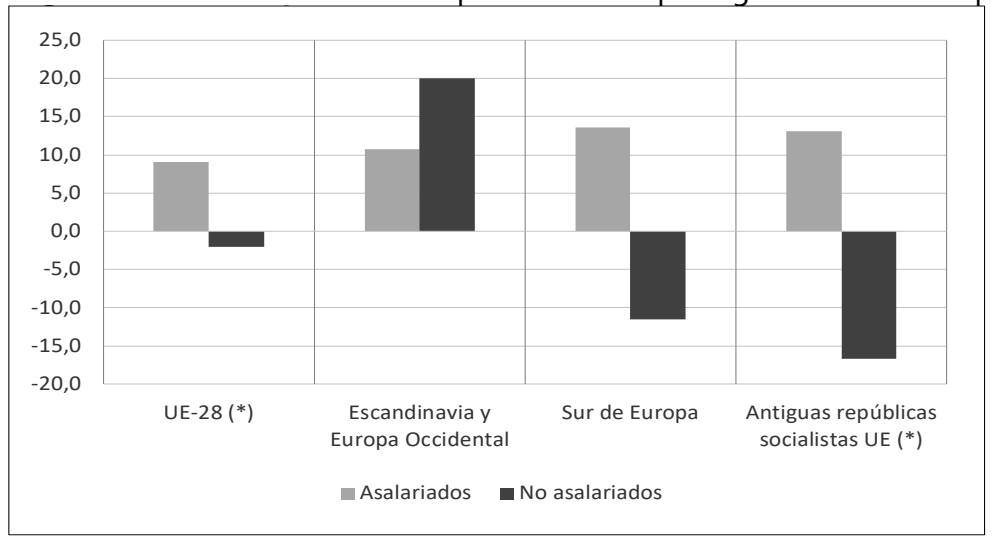

Fuente: Elaboración propia a partir de la European Union Labour Force Survey (Eurostat). Datos anuales, población 15-74 años.

(*) Datos disponibles únicamente a partir de 2002

Gráfico 6 - Tasa de variación del número de trabajadores no asalariados en Europa, 2000-2008 y 2009-2015.

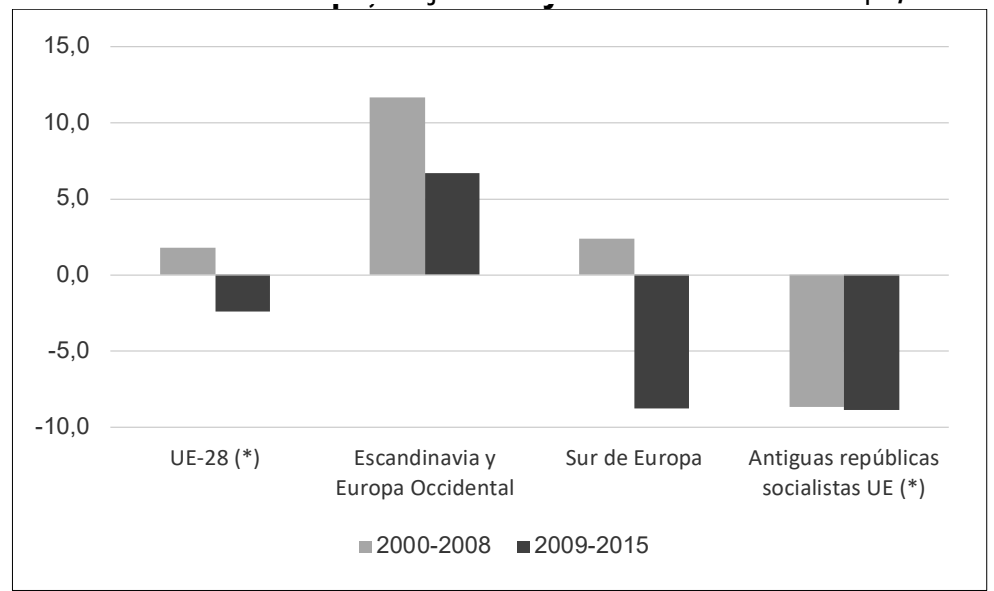

Fuente: Elaboración propia a partir de la European Union Labour Force Survey (Eurostat). Datos anuales, población 15-74 años.

(*) Datos disponibles únicamente a partir de 2002

En el caso de las antiguas repúblicas socialistas es fácil observar (cf. Gráfico 6) que la contracción del trabajo autóno mo ha sido intensa desde el estallido de la crisis económica del año 2008. No obstante, ese mismo gráfico permite también constatar que la destrucción de empleo autónomo en el este de Europa ha sido igualmente intensa antes de la crisis, por lo que no tendría sentido circunscribir a ella las causas de tal transformación. En el sur de Europa, por su parte, la destrucción del trabajo autónomo antes referida sí parece haber estado íntimamente conectada con el estallido de la crisis de 2008 (cf. Gráfico 6). Sin embargo, una ampliación del marco temporal contemplado en nuestro análisis nos permitińa constatarque el proceso de destrucción del trabajo autónomo se remonta a antes de la crisis de 2008. 
Gráfico 7 - Evolución del peso (\%) de los trabajadores agrícolas en el conjunto del empleo dentro de la Unión

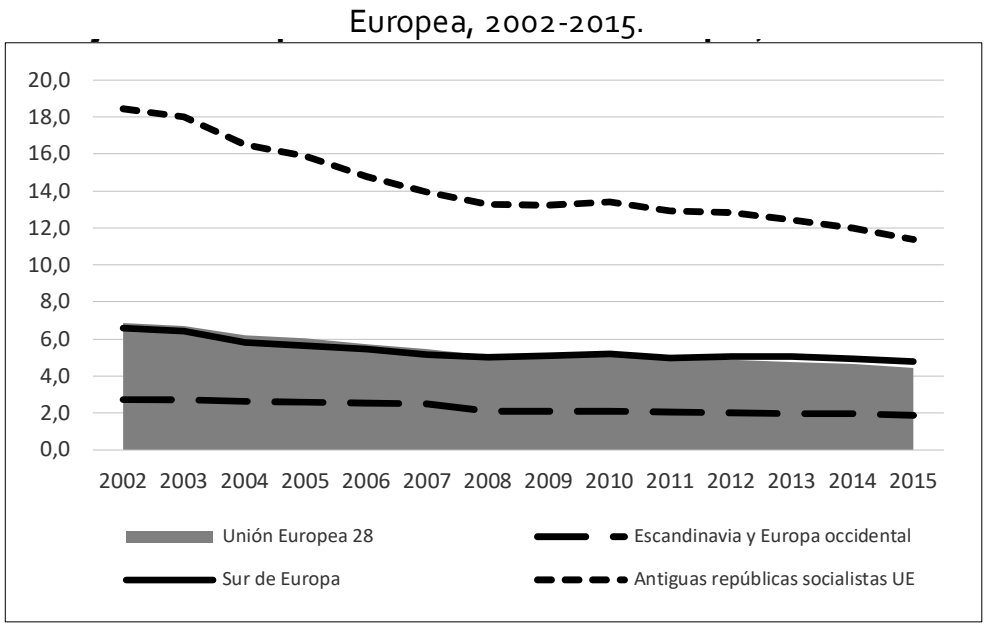

Fuente: Elaboración propia a partir de la European Union Labour Force Survey (Eurostat). Datos anuales, población 15-74 años.

Por ejemplo, entre 1983-2000 Grecia perdió el 4,7\% de su trabajo por cuenta propia (pasando del $51 \%$ al $42 \%$ de los ocupados). Algo parecido ocurrió en Portugal (pérdida del $4,4 \%$ del trabajo porcuenta propia entre 1986-2000 y descenso de su peso relativo del 31\% al $25 \%$ ) y, en menor medida, en España (pérdida del 1,7\% y evolución del peso relativo del $29 \%$ al $20 \%)^{3}$. Vista pues con una mayor perspectiva temporal, la contracción del trabajo autónomo registrada en el sur y este de Europa podría responder parcialmente a un mismo proceso desencadenante registrado en ambas partes de Europa de forma desincronizada: nos referimos a la "modernización" económica derivada de la integración en la UE y la consiguiente reestructuración de sectores tradicionales (como la agricultura) donde históricamente la presencia de trabajo autónomo ha sido elevada (cf. Gráfico 7) ${ }^{4}$.

La destrucción del trabajo autónomo -visible especialmente en el sur y este de Europa - no constituye, sin embargo, el único rasgo significativo de la dinámica del trabajo autónomo en el continente. Tal y como señalábamos más arriba, el trabajo autónomo ha registrado también una dinámica expansiva como respuesta, espontánea o institucionalmente

3 Italia constituye, hasta cierto punto, la excepción pues a pesar de registrar también una pérdida del 1,7\% de sus trabajadores por cuenta propia entre $1983-2000$, el peso relativo se mantuvo bastante estable (del $29 \%$ al 28\%).

4 En España, por ejemplo, la agricultura ha pasado de contar con 2,7 millones de empleos en 1976 (el $21 \%$ de la población ocupada), a sumar apenas 737.00o trabajadores en 2015 (el 4\% de los ocupados). Entre 1987 y 2015 se han perdido casi 1,2 millones de empleos, la gran mayoría de ellos (894.000, el 72\%) empleos de trabajadores autónomos, elevando la tasa de salarización del sector del $27 \%$ al $61 \%$ entre 1987 y 2015 (Instituto Nacional de Estadística, Encuesta de Población Activa). 
organizada, al desempleo creciente y como mecanismo de flexibilización y abaratamientodel mercado de trabajo (cf. European Commission, 2016, 2015a y 2015b; European Employment Policy Observatory, 2014; European Parliament's Committee on Employment and Social Affairs, 2013; Abdelnour, 2013; Eurofound, 2010 y 2002; D'amours, 2009; Muehlberger, 2007). Esta segunda tendencia parece especialmente visible en los países escandinavos y occidentales de Europa, donde la transformación de las estructuras tradicionales de su economía fue más temprana, pero creemos que no se limita exclusivamente a ellos. De hecho, si analizamos, por ejemplo, la evolución del trabajo autónomo controlando la variable del "empleo agrícola" (cf. Gráfico 8) podemos ver que el trabajo autónomo "no agrario" ha crecido -con intensidad diferente- en toda Europa.

Gráfico 8 - Tasa de variación del número de trabajadores autónomos en Europa contabilizando o excluyendo al

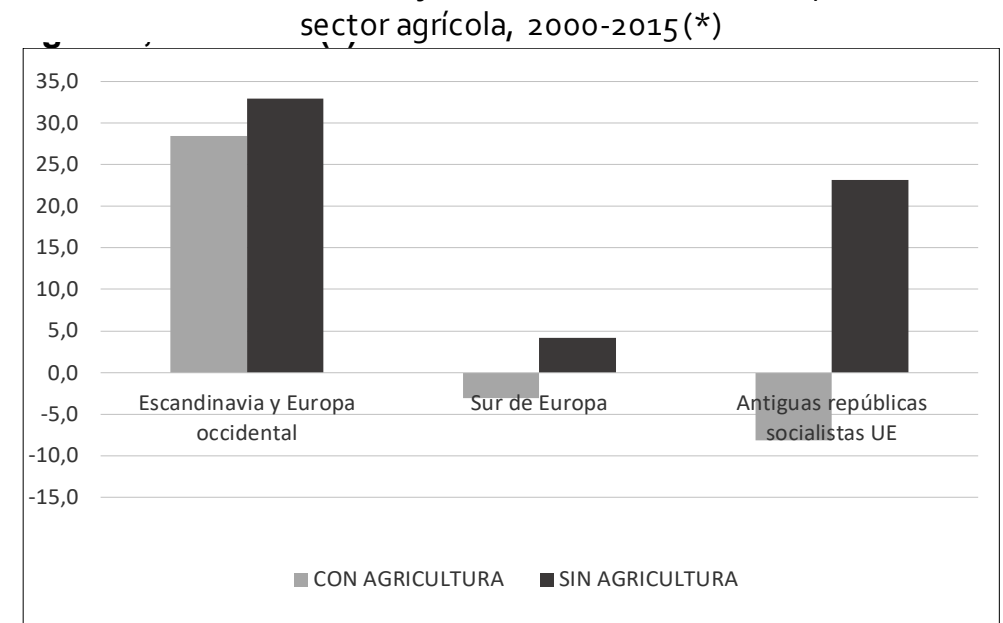

Fuente: Elaboración propia a partir de la European Union Labour Force Survey (Eurostat). Datos anuales, población 15-74 años.

(*) Los datos se refieren únicamente a trabajadores autónomos (con o sin asalariados). En el caso de las anti guas repúblicas socialistas el lapso de tiempo analizado es 2002-2015

Es decir, que el proceso de destrucción del trabajo autónomo registrado en el sur y este de Europa al calor de la reestructuración del sectoragrícola (y del impacto de la crisis de 2008) coexistiría en esos países con un proceso simultáneo de expansión de dicho modo de empleo en otros sectores y actividades. Un proceso pues de expansión común a toda Europa que apunta a una dinámica de cambio más amplia en materia de empleo. Y es que la búsqueda de flexibilidad en el mercado de trabajo es, desde hace décadas, una constante en el espacio europeo que ha cristalizado en múltiples combinatorias de formas "típicas" y 
"atípicas" de empleo que van más allá del recurso al trabajo autónomo5. Es pues en este contexto de cambio más amplio donde habrá que situar y analizar las diferentes intervenciones y reformas que ha registrado el trabajo autónomo en Europa a lo largo de las últimas décadas.

\section{El trabajo autónomo como objeto e instrumento de las políticas públicas europeas}

Aunque el debate y las políticas públicas en torno al denominado emprendizaje están presentes en Europa al menos desde la década de 1980 (Eurofound, 2011a: 7), sU protagonismo ha ido claramente en aumento a lo largo de los últimos años ${ }^{6}$. El trabajo autónomo ha dejado de seridentificado como un indicador de retraso económico, para ser reivindicado -previa mutación discursiva en emprendizaje- en tanto que elemento estratégico para el fomento de la innovación y el crecimiento económico sostenible en la UE (cf. European Commission, 2010). Al mismo tiempo, el trabajo autónomo ha despertado ungran interés entre los responsables políticos como posible mecanismo de creación de empleo, convirtiéndose no en el principal, pero sí en uno de los elementos habitualmente contemplados en las políticas activas de empleo europeas. Un reciente estudio sobre el uso del emprendimiento como mecanismo de lucha contra el desempleo en Europa constataba, por ejemplo, que todos los países de la UE disponían de algún incentivo (a escala nacional, regional o local) para la creación de empresas por parte de desempleados (European Employment Policy Observatory, 2014). Y, en este mismo sentido, otro estudio previo (Eurofound, 2011b) contabilizaba, entre 2008 y 2011, la puesta en marcha en Europa de cerca de 180 medidas de apoyo al trabajo autónomo como vía de creación de empleo: medidas de acceso a financiación, incentivos fiscales, reducción de trámites administrativos, promoción

\footnotetext{
5 Algunas de estas dimensiones las hemos desarrollado con algo más de detalle, aunque de forma aún tentativa, en otro trabajo reciente al que nos remitimos para más detalles: (Célérier, Riesco-Sanz y Rolle, 2019).

6 Sirvan como muestra las iniciativas puestas recientemente en marcha en el seno de la UE con el objetivo de fomentar y facilitar la actividad de las pequeñas y medianas empresas, así como del denominado emprendizaje: la European Charter for Small Enterprises (2000), la Modern SME Policy for growth and employment (2005), la Small Business Act for Europe (2008), la European SME Week (2009), el European Progress Micro-Finance Facility (2010), la Europe 2020 Strategy (2010), el Employment Package (2012), el Entrepreneurship 2020 Action Plan (2013), el Green Action Plan for SMEs (2014), etc. (European Commission, 2016; European Employment Policy Observatory, 2014; European Employment Observatory, 2010).
} 
de la "cultura emprendedora", servicios de orientación, apoyo a la contratación, reformas en la regulación del mercado de trabajo y en materia de seguridad social, etc?7.

El interés que el trabajo autónomo y el denominado emprendizaje ha despertado como herramienta de lucha contra el desempleo se refleja igualmente en la tolerancia o impulso existente en muchos países europeos del emprendizaje a tiempo parcial o de la compatibilidad simultánea de estatutos previamente diferenciados, como ocurre, por ejemplo, con los desempleados a los que se permite compatibilizar, de forma provisional, el ejercicio de una actividad económica porcuenta propia con la percepción de las pres taciones pordesempleo. En conjunto, al menos 15 países de la UE (Bélgica, Bulgaria, República Checa, Alemania, Estonia, Grecia, España, Hungría, Lituania, Polonia, Portugal, Austria, Suecia, Eslovaquia y Finlandia) han impulsado la concesión de subsidios y ayudas no reembolsables a desempleados de cara a su instalación por cuenta propia. En algunos casos (Dinamarca, Holanda o Francia), la percepción de estas ayudas al emprendizaje son compatibles con la percepción (íntegra o aminorada) de las prestaciones por desempleo. Lo más habitual, no obstante, es que dichas ayudas sean concedidas a modo de conversión (capitalización) de la prestación pordesempleo (Bulgaria, España, Francia, Luxemburgo, Portugal) o de reemplazo de la misma (Bélgica, Alemania, Austria, Reino Unido, Finlandia) (European Employment Policy Observatory, 2014: 16-21).

Gráfico 9 - Evolución del gasto público en iniciativas de fomento del emprendizaje y de su peso (\%) sobre total del gasto público en Políticas del Mercado de Trabajo (cat. 2-7)

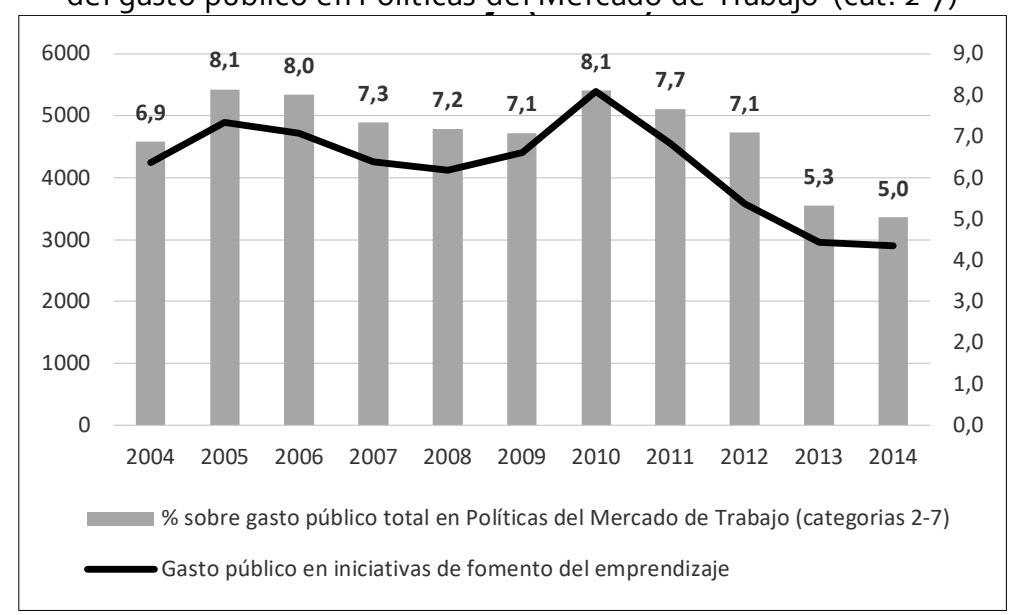

Fuente: Eurostat. Unidad: Millones de euros

7 Un análisis, más detallado y por países, del contenido y características de muchas de estas medidas de fomento del emprendizaje puede verse en: (OECD/European Union, 2015; European Employment Policy Observatory, 2014; Eurofound, 2011b). 
Gráfico 10 - Evolución del no de participantes en iniciativas de fomento del emprendizaje y de su peso (\%) sobre el total de participantes en Políticas del Mercado de Trabajo (cat. 2-7)

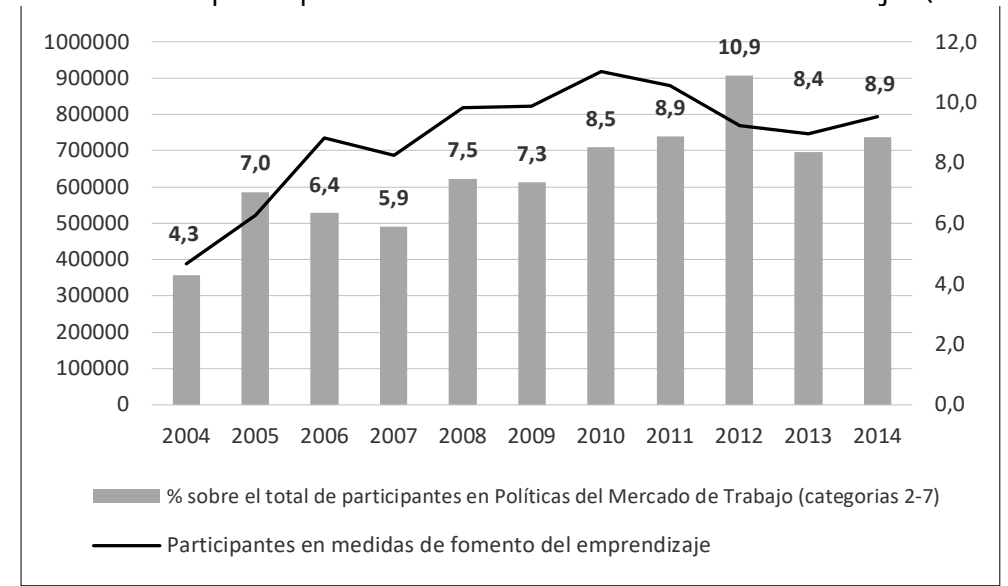

Fuente: Eurostat. Unidad: stock medio anual

Al igual que ocurría con el proceso de destrucción de trabajo no asalariado en Europa, muchas de estas medidas no han sido tampoco un mero producto de la crisis de 2008 , sino que supuesta en marcha (quizá con menos eco mediático y apoyo institucional que ahora) se remonta en muchos casos a la década de 1980: así lo hemos podido constataren un tra bajo anterior respecto al caso francés y español (Célérier, Riesco-Sanz y Rolle, 2016) y así parecen igualmente constatarlo otros estudios que apuntan a que un tercio de los países de la UE habría puesto en marcha incentivos para el emprendizaje de los desempleados desde mediados de la década de 1980 (el resto de países de la UE, en su mayoría, desde 2000) (European Employment Policy Observatory, 2014: 14-15). Por más que la crisis de empleo derivada de la crisis económica de 2008 haya podido relanzar el interés por este tipo de medidas, su presencia y contenido en Europa distan pues de ser novedosos.

Tales medidas de fomento del emprendizaje han tenido, en términos generales, un impacto reducido en materia de creación de empleo desde el estallido de la crisis. Aunque durante los primeros años (2008-2010) se registró un incremento del gasto público europeo en este tipo de políticas, desde 2010 dicho gasto se ha reducido notablemente y, con él, su peso dentro del gasto público total en políticas de empleo, pasando del 8,1\% en 2010 al $5 \%$ en 2014 (cf. Gráfico 9). Algo similar cabe señalar respecto al número de participantes en los programas europeos de fomento del emprendizaje: estos han visto incrementar su número y su peso relativo dentro de las políticas de empleo a lo largo de toda la década de 2000 (desde antes pues del estallido de la crisis), pero desde 2010 (en términos absolutos) y 2012 (en términos relativos) han ido perdiendo protagonismo, pasando de representarel $11 \%$ del total 
de participantes en políticas de empleo en 2012 a representar el 9\% en 2014 (apenas 800.000 trabajadores en toda Europa) (cf. Gráfico 10). Incluso en los países con una mayor tradición en políticas de fomento del autoempleo para desempleados, este tipo de iniciativas apenas suelen afectar a más del $1 \%$ o 2\% de los desempleados registrados, teniendo además una muy escasa capacidad de creación de empleo, más allá del puesto de trabajo del propio autoempleado (European Employment Policy Observatory, 2014: 38-42) ${ }^{8}$.

A estos modestos resultados de las políticas de emprendizaje en materia de creación de empleo habría que añadir la existencia de toda una serie de riesgos asociados a ellas: ingresos variables y a menudo insuficientes; menor o nula protección social del trabajo autónomo; potenciación del fenómeno de los "falsos autónomos" y del recurso a formas de autoempleo poco protegidas como los "autónomos económicamente dependientes"; desplazamiento de asalariados hacia una actividad con un fuerte componente de riesgo, etc. (European Commission, 2016; European Employment Policy Observatory, 2014; Eurofound, 2011a). ¿Cómo entender pues el aparente entusiasmo que, desde hace años, despiertan este tipo de políticas entre gobernantes y responsables políticoseuropeos?

Más allá de componentes puramente ideológicos del discurso del emprendimiento (individualismo, libre empresa, iniciativa privada, independencia, innovación...) que hayan podido seducira determinados gobernantes y organismos públicos, o de la afinidad de tales principios con los presentes en otros procesos de reforma que pudieran estar registrándose en Europa (como los que afectan, porejemplo, a los sistemas de protección social, el auge de las políticas activas de empleo, el denominado paso del welfare al workfare, etc.) (Barbier, 2011; Serrano Pascual y Magnusson, 2007; Kosonen, 1999), la extensión de las iniciativas "emprendedoras" en la agenda europea debería ser puesta también en relación con otras dimensiones más terrenales. Tal y como ha sido señalado (European Employment Policy Observatory, 2014: 11), los programas de fomento del emprendizaje son iniciativas de escaso impacto en la lucha contra el desempleo, pero también de menor coste económico para las

8 El informe sobre la situación del empleo en Europa elaborado por la Comisión Europea (European Commission, 2016: 42) señala, por ejemplo, que sólo un 2,7\% de los desempleados registrados en Europa en 2013 se transformaron en autónomos (sin asalariados) en 2014 (esa misma transformación afectó al 5\% de los inactivos y al 4,5\% de los asalariados). Las cifras son aún inferiores en el caso de la transformación en "autónomos con asalariados": $0,7 \%$ entre los desempleados, 1,2\% entre los inactivos y $3 \%$ entre los asalariados. 
arcas públicas que otros tipos de medidas habitualmente contempladas, como las transferencias de renta a personas y hogares afectados por el desempleo. Los programas de fomento del emprendizaje permitirían pues a los gobernantes e instituciones europeos justificar ante la opinión pública que se están desarrollando iniciativas contra un fenómeno políticamente relevante como es el desempleo, sincomprometer por ello excesivos recursos públicos9.

En definitiva, este tipo de iniciativas -junto a otras que podríamos calificar de ingeniería estadística (definiciones más restrictivas de la categoría "desempleado" en las distintas actuaciones estadísticas e institucionales) y social (multiplicación del empleo registrado en base a la proliferación del trabajo a tiempo parcial, de los contratos de corta duración, de los minijobs, etc.)- permiten a los gobernantes y responsables políticos europeos postergar el abordaje de las causas e implicaciones reales de la crisis del empleo en Europa. Unas causas que no remiten exclusivamente a la actual crisis económica y que no desaparecerán necesariamente una vez se consolide la senda de crecimiento en el continente. Se evacúa así toda discusión pública en torno a un reparto del empleo que, de facto, ya se está produciendo en Europa, pero bajo las peores condiciones posibles para sus ciudadanos: reducción de ingresos (a menudo por debajo incluso de los indicadores de pobreza); trayectorias laborales irregulares y discontinuas; dosis crecientes de precariedady pérdida de derechos; idas y venidas "involuntarias"entre actividad e inactividad; proliferación de formas "atípicas" de empleo dotadas de menores derechos; etc. Des de este punto de vista, podríamos pues concluir que las políticas de emprendizaje europeas han tenido más éxito e impacto en la opinión pública y el terreno político que en la lucha real contra el desempleo, construyendo más voluntades que puestos de trabajo.

A pesar de ello, sería un error por nuestra parte analizarla intervención sobre el trabajo autónomo europeo como un simple reflejo de "tics ideológicos", estrategias políticas o preocupaciones de gobernanza europeos. De hecho, la movilización del emprendizaje como instrumento de lucha contra el desempleo no es el único elemento a destacar en el debate sobre el trabajo autónomo en Europa, ni agota tampoco las intervenciones públicas que éste

\footnotetext{
9 El gasto público en políticas de emprendimiento supuso en 2011 apenas el 0,036\% del PIB europeo (European Employment Policy Observatory, 2014: 11).
} 
ha registrado. Tan o más relevantes para la discusión sobre las transformaciones del empleo en Europa serán las reformas que muchos países europeos están poniendo en marcha a propósito del trabajo autónomo, de la regulación y protección de su actividad.

\section{La reforma del trabajo autónomo en europa: ¿hacia una configuración de estatutos híbridos de empleo?}

Al comienzo de este documento señalábamos cómo el trabajo autónomo vivía en Europa un doble proceso de transformación. Porun lado, veía reducir su presencia en algunos países como consecuencia de la contracción de sectores tradicionalmente relevantes para este modo de empleo (como la agricultura). Pero, por otro lado, el trabajo autónomo registraba un incremento de su presencia en otros muchos sectores al calor del proceso de flexibilización del mercado de trabajo europeo, de la irrupción del capitalismo de platafoma y de los cambios registrados en la organización y funcionamiento de la empresa como uno de los actores responsables del agenciamiento y puesta en relación de factores productivos diversos. Veíamos también que esta extensión de determinadas modalidades de empleo por cuenta propia en Europa no constituía un fenómeno aislado, sino que debía ser puesto en relación con un proceso más amplio de diversificación de las modalidades de uso de la fuerza de trabajo en el que el recurso al trabajo autónomo sería una de sus expresiones (International Labor Organisation, 2016). Es en este contexto donde tendríamos que situar y analizar la creciente actividad reformista de no pocos Estados europeos con respecto al trabajo autónomo y, en particular, en relación a determinadas modalidades del mismo de condición ambigua, a caballo entre la independencia y la subordinación, como el denominado "trabajo autónomo económicamente dependiente ${ }^{110}$.

Muchos de los países que conforman la Unión Europea han conocido en los últimos años algún tipo de debate en torno a la correcta delimitaciónjurídica del trabajo autónomo.

\footnotetext{
${ }^{10}$ A partir de los datos de la 5th European Working Conditions Survey (2010) de Eurofound podemos estimar que los trabajadores autónomos económicamente dependientes (con al menos el $75 \%$ de sus ingresos procedentes de un único empleador) representaban el 22\% del total de los trabajadores autónomos de la UE 28. Ese peso se incrementa hasta el $39 \%$ si definimos como "económicamente dependientes" a aquellos autónomos cuyos ingresos dependen al menos en un 50\% de un único cliente. En este último caso, nos encontraríamos con que, por ejemplo, los autónomos económicamente depe ndientes representan el 16,5\% del total de los ocupados en el sector agrícola o el 6,6\% en el caso de las actividades profesionales y artísticas, datos que apuntan a que no estamos ante una categoría de empleo meramente residual en Europa.
} 
Es decir, en realidad en torno a los principios, supuestos y mecanismos por medio de los cuáles las distintas y cada vez más heterogéneas modalidades de participación en el mercado de trabajo deberían o no integrarse en el estatuto del trabajo asalariado y participar de sus instituciones. Estos debates se han acompañado de discusiones acerca de los derechos del trabajo autónomo (y de otras modalidades no convencionales de empleo), así como sobre las posibles vías de mejora de su protección. No obstante, la envergadura de los cambios que dichas reformas supond rían (no sólo a nivel de la normativa laboral de cada país, sino también en el ámbito fiscal, en los sistemas de seguridad social, en la prestación por desempleo, etc.), han limitado a menudo la plasmación de estos debates en iniciativas concretas (Eurofound, 2010: 14). La consecuencia de todo ello ha sido que la diferenciación jurídica entre independencia y subordinación, constitutiva del estatuto tradicional del trabajo asalariado, se ha mantenido como eje de la regulación del empleo en la mayoría de los países. No obstante, pese a esta continuidad de fondo, podemos atisbar en Europa dos estrategias o vías diferenciadas de afrontar los desafíos que el trabajo autónomo -sobre todo bajo sus modalidades de trabajo autónomo económicamente dependiente- supone para los regímenes de empleo y protección social europeos.

Tendríamos, por un lado, países como Alemania (Eurofound, 2010: 16 y ss.), que han tratado de hacer frente a esta creciente diversidad y ambigüedad en los usos de la fuerza de trabajo con una cierta reafirmación del estatuto del trabajo asalariado. Este tipo de respuestas habría tratado de reabsorber, dentro del estatuto del trabajo asalariado ya existente, al mayor número posible de situaciones atípicas de empleo. ¿Cómo? Mediante la incorporación de una mayor flexibilidad en la definición de la condición asalariada (exigencia de que se cumplan al menos tres criterios de un listado más amplio de condiciones en lugar de ofrecer una definición rígida y cerrada ${ }^{11}$ ) y, por lo tanto, atribuyendo un mayor protagonismo a los tribunales del trabajo como intérpretes de dicha flexibilidad conceptual. Sin negar la posible presencia de otras vías de precarización del empleo en el país (fomento del trabajo a tiempo parcial, reducción de derechos adscritos al trabajo asalariado,

\footnotetext{
${ }^{11}$ Por ejemplo: no tener asalariados a su cargo, trabajar habitualmente para un único cliente, haber realizado previamente el mismo trabajo en calidad de asalariado, realizar actividades idénticas a las que realizan en la empresa otros trabajadores asalariados, no haber iniciado el trabajador ninguna actividad emprendedora, etc. (Eurofound, 2010: 16-17).
} 
ampliación de los tiempos de trabajo y pérdida de poder adquisitivo, etc.), el ejemplo alemán (u otros como el francés o el belga) parece haber apostado fundamentalmente por mantener al trabajo asalariado y su estatuto (es verdad que un estatuto de contenidos progresivamente "debilitados") como eje de la regulación y protección en torno al cual gravitarían otras modalidades menos convencionales de uso de la fuerza de trabajo.

Frente a este tipo de respuestas -en realidad de forma paralela a las mismas- nos encontramos con que un buen número de países europeos están formalizando y regulando algunas de estas fórmulas "atípicas" de utilización de la fuerza de trabajo. Más que diluirlas o absorberlas dentro de los límites del estatuto del trabajo asalariado tradicional, este otro tipo de respuestas estarían impulsando -con un grado muy desigual de formalización- modos de uso de la fuerza de trabajo que se sitúan en una posición intermedia entre la subordinacióny la independencia, configurando así estatutos híbridos de empleo que comparten muchas de las dependencias características del trabajo asalariado pero carecen con frecuencia de sus mecanismos básicos de protección (Martín Puebla 2012; Schmid, 2011; Consejo Económico y Social Europeo 2010; Perulli 2003; Supiot 2000) ${ }^{12}$.

Austria, por ejemplo, ha impulsado desde 1997 el "free service contract" pretendiendo con ello ampliarla protección social de ciertos tipos de trabajadores autónomos. Este tipo de contrato estaría destinado a trabajadores excluidos formalmente de una relación de empleo subordinada pero que suelen prestar sus servicios para un cliente único o principal y, a menudo, con horarios fijos de trabajo. Mediante este contrato se reconocería la existencia de algún tipo de dependencia o subordinación en la condición independiente propia del autónomo, garantizándole porley algunas protecciones básicas del trabajo asalariado(salud, accidentes laborales, jubilación), aunque excluyéndole de otras importantes (como el desempleo) (Eurofound, 2010: 28). Italia, porsu parte, contaba, hasta su reciente derogación en 2016 , con los contratto di collaborazione a progetto (co.co.pro), un contrato de trabajo

\footnotetext{
12 En una reciente nota de investigación auspiciada por la European Commission (Fondeville et al., 2015: 39), se apuntaba que todos los países de la UE daban algún tipo de protección por jubilación a los autónomos; todos, a excepción de 4, ofrecían protección por enfermedad y 17 algún tipo de protección por desempleo. Estos datos muestran una cierta preocupación por la protección del trabajo autónomo en Europa, si bien, como sabemos, los problemas radican muchas veces en la cuantía de las prestaciones, su carácter voluntario o insuficiente. El caso español, abordado más abajo, es altamente ilustrativo al respecto.
} 
destinado a trabajadores freelance en situación de dependencia económica. Es decir, trabajadores autónomos que, dentro de un marco de referencia fijado en dos años, hubieran cumplido con al menos dos de las siguientes condiciones: haber colaborado con el cliente más de 8 meses, haber obtenido de dicho cliente el 80\% de sus ingresos durante ese periodo o, finalmente, disponer de un puesto de trabajo fijo en las instalaciones del cliente (Terrasse, Barbezieux y Herody, 2016: 9213.

No obstante, uno de los casos más llamativos y ambiciosos de este segundo tipo de respuestas que estamos analizando lo constituye el caso español (Riesco-Sanz, 2016), sobre el que merece la pena que nos detengamos un momento. En 2007 España aprobaba la Ley 20/2007, de 11 de julio, del Estatuto del Trabajo Autónomo (LETA) (Jefatura del Estado 2007) y, en definitiva, la creación de un régimen profesional específico para los autónomos que se convertiría en el marco normativo de referencia. Un marco regulador aprobado por unanimidad en el Parlamento español y que el regreso en 2011 de la derecha al gobierno más allá de un cierto desplazamiento simbólico del "trabajador autónomo" (a proteger) al "emprendedor" (a liberar)- apenas habría modificado ${ }^{14}$. De este modo, España apostaba no sólo por reconocer el trabajo autónomo económicamente dependiente, tal y como habían hecho otros países, sino por configurar un estatuto específico para el trabajo autónomo. Un marco regulador y protector de la relación de empleo contemporánea no fundamentado en el principio de subordinaciónjurídica y que define el trabajo autónomo en términos positivos y no únicamente como aquello que no es trabajo asalariado. Ahora bien, este reconocimiento de un estatuto de empleo específico para el trabajo autónomo en España ¿habría supuesto una diferenciación más profunda con respecto al trabajo formalmente asalariado? Creemos que no, más bien al contrario.

13 Este nuevo marco regulatorio, ligeramente más garantista, destinado a los autónomos económicamente dependientes no era, sin embargo, aplicable en caso de actividades altamente cualificadas, de superar un determinado umbral de ingresos $(18.000 €)$, de formar parte de algún colegio profesional (como los abogados) o de que el cliente pudiera demostrar que el colaborador era un verdadero trabajador autónomo (Terrasse, Barbezieux y Herody, 2016: 92).

${ }_{14}$ El nuevo gobierno conservador del Partido Popular se ha centrado, principalmente, en desarrollar medidas complementarias de promoción de la empresarialidad, de apoyo fiscal y de bonificaciones a la contratación para los trabajadores autónomos y para las pequeñas empresas, medidas muchas de ellas recogidas en la Ley de Apoyo a los Emprendedores y su Internacionalización (Jefatura del Estado 2013) y, posteriormente, en la Ley de Fomento del Trabajo Autónomo (Jefatura de Estado, 2015). 
La aprobación del Estatuto del Trabajo Autónomo ha generado en España una cierta confluencia (sin duda incompleta) entre ambos modos y estatutos de empleo históricamente diferenciados. Dicha confluencia resulta evidente, por ejemplo, en el reconocimiento a los trabajadores autónomos por parte de la LETA de un buen número de derechos fundamentales -individuales y colectivos- propios del trabajo asalariado: derecho de asociación, representación y defensa colectiva de los intereses profesionales; derecho a la conciliación de la vida personal y familiar; a la seguridad y salud en el trabajo, etc. La LETA y sus desarrollos posteriores (Jefatura del Estado 2010; Ministerio de Trabajo e Inmigración, 2009)- ha extendido asimismo a los autónomos una serie de protecciones y prestaciones económicas históricamente ligadas al trabajo asalariado: asistencia sanitaria en caso de maternidad, de enfermedad común o profesional; prestaciones en caso de accidente, muerte o jubilación, así como la posibilidad de acceder a una prestación económica por cese de actividad financiada a través de las propias cotizaciones sociales de los trabajadores autónomos.

La confluencia de estatutos entre trabajo autónomo y trabajo asalariado resulta a ún más evidente en la nueva categoría de autónomos creada por la LETA: los Trabajadores Autónomos Económicamente Dependientes (TRADE) ${ }^{15}$. Por ejemplo, la LETA establece la obligatoriedad de que las empresas demandantes de la prestación de servicios y los autónomos TRADE fijen un contrato de trabajo por escrito en el que se explicite, entre otros aspectos, el tiempo de trabajo y de reposo semanal/anual del autónomo. La LETA reconoce igualmente a este tipo de autónomo el derecho a una pseudo negociación colectiva que podría derivar -aunque su eficacia ha sido relativizada (Castro 2011; Cairós 2008) - en la firma de "Acuerdos de Interés Profesional" entre las organizaciones sindicales o profesionales de los autónomos y las empresas en las que selleva a cabo su prestación de trabajo. Finalmente,

15 La LETA española define a los trabajadores autónomos económicamente dependientes (TRADE) como aquellos que "realizan una actividad económica o profesional a título lucrativo y de forma habitual, personal, directa y predominante para una persona física o jurídica, denominada cliente, del que dependen económicamente por percibir de él, al menos, el 75 por ciento de sus ingresos por rendimientos de trabajo y de actividades económicas o profesionales". Debemos señalar, no obstante, el éxito reducido que ha tenido esta nueva figura: según los datos de afiliación a la Seguridad Social del Ministerio de Empleo y Seguridad Social, a 31 de diciembre 2015 había 9.851 contratos TRADE registrados, cuando diferentes estudios (Agut y Nuñez, 2012; Asociación de Trabajadores Autónomos, 2006) habían estimado en unos 300.000 (alrededor del $14 \%$ del total de autónomos) los trabajadores autónomos que podrían potencialmente formar parte de dicho colectivo y beneficiarse de los mecanismos de protección previstos para ellos. 
lo que no deja de ser significativo, la LETA reconoce a la jurisdicción social, es decir, al Derecho del Trabajo propio del trabajo asalariado, la competencia para resolver los conflictos laborales de los TRADE.

Este movimiento de confluencia de estatutos que aquí estamos señalando debería ser, no obstante, matizado como hipótesis, al menos en lo que a su alcance actual se refiere. El nuevo marco regulador del trabajo autónomo en España ha mantenido un sistema fiscal específico para el mismo, así como un régimen de Seguridad Social-el Régimen Especial del Trabajo Autónomo (RETA) - que, desde su creación en 1970 y pese a las transformaciones registradas, se ha caracterizado portener cotizaciones sociales más bajas y, en conse cuencia, por prestaciones y mecanismos de protección más limitados. Así, por ejemplo, en 2013, las bases medias de cotización de los trabajadores afiliados al Régimen General de la Seguridad Social se estimaron en $1.739 € /$ mes, mientras que las bases medias del RETA fueron de 1.030 $€ /$ mes (CEPYME 2013: 35), un dato poco sorprendente si tenemos en cuenta que -según datos del Ministerio de Empleo y Seguridad Social (2016) - de los algo más de 3 millones de autónomos registrados en el RETAa 31 de diciembre de 2015, el 67,3\% cotizaba con las bases mínimas de la Seguridad Social $(884,40 €)$.

En lo que se refiere a la prestación por jubilación, las cantidades percibidas por los trabajadores autónomos a través de la Seguridad Social son aún reducidas y muy inferiores (el 38\%) a las del Régimen General donde se integra el grueso de los asalariados (Unión de Profesionales y Trabajadores Autónomos, 2012). Por otro lado, en 2012 sólo un 21\% del total de trabajadores autónomos inscritos en la Seguridad Social disponía del seguro por cese de actividad -obligatorio para los TRADE, voluntario para el resto de autónomos - instaurado por la LETA (Unión de Profesionales y Trabajadores Autónomos 2012), frente al 38\% de cobertura existente para el conjunto de la población activa (el 78\% si no contabilizamos únicamente las prestaciones contributivas por desempleo) (Instituto Nacional de Estadística, Indicadores Sociales 2011). Datos como estos nos impiden pues poder afirmar que la igualdad de derechos entre ambos modos de empleo sea hoy una realidad plena. La confluencia de estatutos profesionales y la conformación de estatutos híbridos de empleo aquí sugerida debería ser pues abordada como una tendencia de cambio de largo recorrido inscrita en la propia evolución de los sistemas de protección social del trabajo en España. Una tendencia que, a distintos niveles y con diferentes grados de intensidad, estaría también registrándose en otros puntos de Europa, tal y como acabamos de ver. 
De hecho, los dos tipos de respuestas que hemos mencionado no constituyen, en realidad, estrategias unívocas por parte de quienes las han puesto en marcha. Países como Alemania y Francia, donde predomina aún la absorción de las nuevas formas de empleo en el estatuto tradicional del trabajo asalariado, han impulsado igualmente el reconocimiento de algunas de estas categorías híbridas de empleo antes mencionadas. Alemania, por ejemplo, ha formalizado la categoría de los arbeitnehmeränliche person para reconocer a los trabajadores autónomos económicamente dependientes (definidos como aquellos que ejecutan su trabajo para un único cliente o que perciben de él más del 50\% de sus ingresos) algunos derechos (limitados) de protección propios de los asalariados (Terrasse, Barbezieux y Herody, 2016: 91). Mientras que Francia, por su parte, ha impulsado desde 2009, por ejemplo, el régimen de los auto-entrepreneurs, configurando con ello una figura de emprendedor que se mueve en el ámbito de la independencia, pero al cual se adscriben, de cara a su protección, elementos fundamentales del salario social : protección por enfermedad, jubilación, prestaciones por paternidad/maternidad, etc. (Célérier, Riesco-Sanz y Rolle, 2016). Del mismo modo, España, que parece haber apostado, al contrario que Francia o Alemania, por dotar de un estatuto de empleo específico -diferenciado formalmente del estatuto del trabajo asalariado-a algunos de estos nuevos usos de la fuerza de trabajo, no ha cesado de efectuar una constante labor de interpretación de las siempre móviles fronteras formales del trabajo asalariado. Por medio de la actuación de sus tribunales del trabajo, actividades inicialmente concebidas como ejercidas por cuenta propia han terminado siendo recualificadas como "asalariadas" $y$, por lo tanto, englobables dentro de la tutela del derecho del trabajo y de las instituciones tradicionales del trabajo asalariado ${ }^{16}$.

Aunque distintas en sus motivaciones, contenidos e implicaciones, todas estas reformas muestran una transformación en marcha del estatuto tradicional del trabajo asalariado y señalan, al mismo tiempo, la necesidad que registran los diferentes Estados europeos de intervenir ante un proceso de recomposición global de las modalidades de movilizacióny uso de la fuerza de trabajo que ellos mismos han contribuido a desarrollar. Un proceso de recomposición que apunta a una profundización de la desvinculación de los trabajadores con respecto a sus empleos y, consecuentemente, a una mayor complejización

\footnotetext{
${ }^{16}$ Se puede ver un análisis de la jurisprudencia española entre 1980 y 2008 en (Martín Valverde, 2002 y 2009 ).
} 
de las modalidades y estructuras usuarias de dicha fuerza de trabajo. La pregunta es ¿acaso dicha complejidad incrementada no deberá encontrar su reflejo también en los dispositivos de observación que movilizamos los investigadores para tratar de dar cuenta de ella?

\section{El trabajo autónomo: una oportunidad para pensar el salariado en térm inos ampliados}

A pesar de las reformas emprendidas, en la mayoría de los países europeos, la calificación de una relación laboral como asalariada sigue dependiendo, desde el punto de vista del derecho, de la posibilidad de celebrar un contrato de trabajo, es decir, de la existencia en ella de una relación de dependencia del trabajadorcon respecto a su empleador (Rodríguez-Piñero 1999; Montoya 1999). No se trata, sin embargo, de cualquier tipo de dependencia: descartadas en el debate jurídico las dimensiones sociales y económicas de la misma, ha sido la construcciónjurídica de la subordinación (el poder de dirección ejercido por uno de los contratantes sobre la prestación de actividad del otro) el criterio utilizado para diferenciar el trabajo asalariado de las formas de trabajo "no subordinadas" (Lefebvre 2009; Rodríguez Piñero 1999).

El principio de subordinación jurídica ha desempeñado, por lo tanto, un papel históricamente determinante a la hora de establecer las fronteras del trabajo asalariado e, indirectamente, de cara a delimitarotras modalidades de prestación laboral (Lefebvre 2009; Didry y Brouté 2006, Chauchard y Hardy-Dubernet 2003; Supiot 2000; Cruz Villalón 1999). No se trata de una cuestión menor: dicha operación delimitadora ha supuesto también el establecimiento de los criterios de acceso (o exclusión) al estatuto del trabajo asalariado que fue progresivamente conformándose desde la segunda mitad del siglo XIX, es decir, a sus derechos, mecanismos de regulación e instituciones protectoras. De este modo, por medio de la construcción jurídica del principio de subordinación, trabajo asalariado y trabajo autónomo han quedado históricamente configurados como dos modos de empleo formalmente contrapuestos y casi podríamos decirque antagónicos, algo que, sin embargo, no siempre resulta evidente. El principio de subordinación jurídica al que nos venimos refiriendo queda, por ejemplo, a menudo desfigurado en las denominadas nuevas formas de organización del trabajo. Éstas apelan con frecuencia a la capacidad de iniciativa y autonomía de los trabajadores (asalariados) en lo que se refiere a la ejecución de tareas y a la organización del proceso de trabajo (círculos de calidad y grupos semi -autónomos, trabajo 
por proyectos, etc.) (Durand 2012; Lahera Sánchez 2005; Boltanski y Chiapello 2002). La extensión de la subcontratación y la externalización de servicios, por otra parte, suponen al mismo tiempo un recurso a trabajadores y empresas formalmente independientes pero, muchas veces, sujetos de facto a los criterios y ritmos organizativos, a las consignas y estrategias de las empresas contratantes (por ejemplo, en materia de estándares de calidad y procedimientos de fabricación, tiempos de trabajo, etc.) (Perraudin, Thévenot y Valentin 2013; Lebeer y Martínez 2012).

La propia ciencia jurídica -junto al resto de ciencias sociales del trabajo- ha reconocido la dificultad de mantener distinciones netas entre unos y otros estatutos en las denominadas "zonas grises" del mercado de trabajo (Martín Valverde 2009; Cairós 2008; Alonso 2004; Supiot 1999). Muy a menudo, la práctica jurídica se ve en la obligación de movilizar un abanico heterogéneo de indicios de cara a establecersi determinadas relaciones laborales son o no asalariadas, desplazando progresivamente unas fronteras del trabajo asalariado que se muestran más porosas y dinámicas de lo que dejaba entrever su formalización inicial. Las propias instituciones vinculadas al trabajo asalariado (como, por ejemplo, el contrato de trabajo o el sistema de cotizaciones y prestaciones sociales que desembocará en la creación de la Seguridad Social), se generalizan más allá de los segmentos específicos de población trabajadora en los que habían quedado inicialmente circunscritos (Friot 2012; Castel 1997; Martín Valverde 1990; Rolle 1988). Dichas instituciones no sólo se extienden a nuevos segmentos del trabajo -personal del servicio doméstico y campesinado, artistas, cuadros directivos y profesionales, representantes del comercio y determinadas profesiones liberales (abogados, médicos, arquitectos)- sino que van más allá de los trabajadores en activo propiamente dichos (estudiantes, jubilados, enfermos...), conformando estructuras capaces de afectar a amplias franjas de la población, cuando no a la evolución del conjunto de la sociedad. ¿Por qué restringir entonces nuestro análisis al empleo -formalmente- asalariado en lugar de hablar de sociedad salarial o salariado? La demarcación jurídica de la relación moderna de trabajo ¿resulta suficiente para investigar la dinámica global del empleo?

Movilizando distintos tipos de instituciones -entre ellas, de manera destacada, la Seguridad Social-, los Estados intervienen más allá de los límites estrictos del estatuto profesional, garantizando al conjunto de trabajadores protecciones y derechos tradicionalmente vinculados al trabajo (formalmente) asalariado. Dicha actuación nos coloca 
ante un escenario aparentemente contradictorio en el que la continua proliferación de nuevos modos de empleo y estatutos profesionales convive con una (relativa) tendencia a homogeneizarlas "condiciones de uso" de amplios segmentos de la fuerza de trabajo. Un escenario quizá menos sorprendente si consideramos las necesidades de coordinación y combinación derivadas de los dispositivos productivos contemporá neos, dispositivos en red en los que la intervención de una multitud de sujetos productores no pasa necesariamente por su adscripción a una estructura organizativa tipo empresa.

La regulación y reforma del trabajo autónomo en Europa a la que aquí hemos hecho brevemente referencia constituye un buen ejemplo de esta participación activa del Estado a la hora de establecer criterios comunes de utilización de la fuerza de trabajo más allá del estatuto profesional considerado. Con su actuación el Estado regula las condiciones de entrada y de salida de los nuevos estatutos de empleo a los formaliza, definiendo su posible compatibilidad con otros regímenes profesionales. Interviene también en el coste, la duración y las modalidades de uso de esta fuerza de trabajo jurídicamente no subordinada, en la definición de no pocos aspectos de sus trayectorias profesionales y de sus propias condiciones de trabajo. Incide en la renta disponible $-y$, en definitiva, en las condiciones de reproducción y bienestar de estas poblaciones-por medio de la aplicación de diferentes medidas fiscales y de la institucionalización de cotizaciones y seguros obligatorios frente a ciertos riesgos comunes a la actividad laboral en el salariado.

Desde esta perspectiva, el análisis del trabajo autónomo y del trabajo asalariado a partir de su delimitación jurídica resulta insuficiente y su o posición formal poco relevante. La dinámica del trabajo autónomo en Europa apunta, sin duda, a importantes transformaciones y fracturas del vínculo salarial tradicional, pero también a una diversificación de las vías de participación en la generación y disfrute de la riqueza socialmente producida y, de manera más general, a una pluralidad de vías de participación en las instituciones que perpetúan y renuevan el salariado. Si, como aquí proponemos, el trabajo autóno mo constituye en realidad una de las combinaciones posibles de encuentro (provisional) entre capacidades productivas y actividades dentro del salariado, será entonces en el seno de este movimiento de mayor calado como podremos avanzar tentativamente una explicación de la propia dinámica y transformación del trabajo autónomo contemporáneo. Dicho en otras palabras, lo que aquí estamos considerando de cara a avanzar en nuestra comprensión de la transformación del empleo es la necesidad de abordar las transformaciones del trabajo autónomo como parte 
de la propia dinámica del salariado, más allá pues de las fronteras formales dibujadas en tomo a éste o aquel régimen profesional, modo de empleo o estatuto laboral. Un salariado sin duda transformado, entre otras muchas cosas por la propia realidad contemporánea del trabajo autónomo, pero cuya eventual disolución quedaría aún por demostrar (desde un punto de vista explicativo) y explorar (des de una perspectiva política o ciudadana).

\section{Referencias}

ABDELNOUR, Sarah. L'entrepreneuriat au service des politiques sociales: La fabrication du consensus politique sur le dispositif de l'auto-entrepreneur", Sociétés contemporaines, 89, pp. 131-154, 2013.

ALONSO, Luis Enrique. La sociedad del trabajo: debates actuales. Materiales inestables para lanzar la discusión", Revista Española Investigaciones Sociológicas 107(4), pp. 21-48, 2004.

ASOCIACIÓN DE TRABAJADORES AUTÓNOMOS. Informe del trabajo autónomo dependiente.

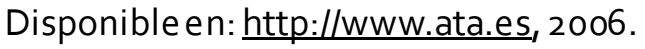

AGUT, Carmen; NÚÑEZ, Cayetano. La regulación del trabajo autónomo económicamente dependiente en España: un análisis crítico comparado con Italia, Working paper 124. Associazione pergli Studi Internazionali e Comparati sul Diritto del Lavoro e sulle Relazioni Industrialli, 2012.

BARBIER, Jean Claude. Activer les pauvres et les chômeurs par l'emploi? Leçons d'une stratégie de réforme, Politiques Sociales et Familiales, 104, p. 47-58, 2011.

BOLTANSKI, Luc; Chiapello, Eve. El nuevo espíritu del capitalismo. Madrid: Akal, 2002.

CAIRÓS, Dulce. Acerca de la denominada crisis del contrato de trabajo tradicional y la aportación española: el estatuto del trabajo autónomo. Gaceta Laboral, v. 14, n. 2, p. 193-219, 2008.

CASTEL, Robert. Las metamorfosis de la cuestión social. Una crónica del salariado, Buenos Aires, Paidós, 1997.

CASTRO, María A. Los acuerdos de interés profesional: un balance de la negociación llevada a cabo al amparo del estatuto del trabajo autónomo, Anales de derecho, 29, p. 34-80, 2011.

CÉLÉRIER, Sylvie; RIESCO-SANZ, Alberto; ROLLE, Pierre. Figures de travailleur - figures d'entrepreneur? Les diverses voies européennes de détachement des travailleurs de l'entreprise. In: ARBORIO Anne-Marie; BOUFFARTIGUE, Paul; LAMANTHE, Annie (dir.) Crise(s) et mondes du travail, Toulouse, Éditions Octares, p. 35-48, 2019.

CÉLÉRIER, Sylvie; RIESCO-SANZ, Alberto; ROLLE, Pierre. Une indépendance équivoque: les nouveaux statuts des indépendants espagnols et français, Revue Française de Socio-Economie, 17, pp. 21-41, 2016.

CONFEDERACIÓN ESPAÑOLA DE LA PEOUEÑA Y MEDIANA EMPRESA. Análisis del Régimen Especial de Trabajadores Autónomos en el sistema nacional de la Seguridad Social. Madrid, CEPYME, 2013. 
CONSEJO ECONÓMICO Y SOCIAL EUROPEO. New Trends in Self-Employed Work: The Specific Case Of Economically Dependent Self-Employed Work. Soc/344 - cese 639/2010. Bruselas: Consejo Económico y Social Europeo, 2010.

CRUZ VILLALÓN, Jesús (ed.). Trabajo subordinado y trabajo autónomo en la delimitación de fronteras del Derecho del Trabajo, Madrid: Tecnos, 1999.

CHAUCHARD, Jean Pierre: HARDY-DUBERNET, Anne Chantal (dir.) La subordination dans le travail. París: La documentation française, 2003.

D'AMOURS, Martine. Travail précaire et gestion de risques: vers un nouveau modèle social? Lien social et Politiques, 61, p. 109-121, 2009.

DIDRY, Claude; BROUTÉ, Rémi. L'employeur en question, les enjeux de la subordination pour les rapports de travail dans une société capitaliste". In: PETIT, Héloïse; THĖVENOT, Nadine (dir.) Les nouvelles frontières du travail subordonné, París: La Découverte, p. 47-70, 2006.

DURAND, Jean Paul. La cadena invisible. Flujo tenso y servidumbre voluntaria, México DF: Fondo de Cultura Económica, 2012.

EUROFOUND. Emerging forms of entrepreneurship. Dublín: Eurofound, $2011 a$.

EUROFOUND. Public measures to support self-employment and job creation in one-person and micro enterprises. Dublín; Eurofound, 2011b.

EUROFOUND. Self-employed workers: industrial relations and working conditions. Dublín: Eurofound, 2010.

EUROFOUND. 'Economically dependent workers', employment law and industrial relations, Dublín: Eurofound, 2002.

EUROPEAN COMMISSION. Employment and Social Developments in Europe 2015, Bruselas, DG for Employment, Social Affairs and Inclusion, European Commission, 2016.

EUROPEAN COMMISSION. Policy Brief on Informal Entrepreneurship. Entrepreneurial Activities. In: Europe, Bruselas, European Commission/OECD, 2015 a.

EUROPEAN COMMISSION (2015b)Recent changes in self-employment and entrepreneurship across the EU. Social Situation Monitor, Researchnote 6/2015. Bruselas, DG for Employment, Social Affairs and Inclusion, European Commission, 2015b.

EUROPEANCOMMISSION. Europe 2020. A strategy for smart, sustainable and inclusive growth, Bruselas, European Commission [COM(2010)2020], 2010.

EUROPEAN EMPLOYMENT OBSERVATORY. Self-employment in Europe 2010. Bruselas, DG for Employment, Social Affairs and Equal Opportunities, European Commission, 2010.

EUROPEAN EMPLOYMENT POLICY OBSERVATORY. Activating jobseekers through entrepreneurship: start-up incentives in Europe. Bruselas, DG for Employment, Social Affairs and Equal Opportunities, European Commission, 2014. 
EUROPEAN PARLIAMENT'S COMMITTEE ON EMPLOYMENT AND SOCIAL AFFAIRS. Social protection rights of economically dependent self-employed workers. Bruselas, European Parliament, DG for Internal Policies[IP/A/EMPL/ST/2012-02], 2013.

FONDEVILLE, Nicole; OZDEMIR, Erhan; LELKES, Orsolya; WARD, Terry. Recent changes in selfemployment and entreprenership across the EU. Bruselas, European Commission, Research note n० 6/2015, 2015.

FRIOT, Bernard. Puissances du salariat (nouvelle édition augmentée), París: La Dispute, 2012.

INTERNATIONAL LABOR ORGANISATION. Non-standard Employment Around the World: Understanding challenges, shaping prospects, Ginebra: International Labor Organisation, 2016.

JEFATURA DEL ESTADO. Ley 20/2007, de 11 julio. Boletín Oficial del Estado, 166, p. 29964-29978, 2007.

JEFATURA DEL ESTADO. Ley 32/2010, de 5 de agosto. Boletín Oficial del Estado, 190, p. 68526$68551,2010$.

JEFATURA DEL ESTADO. Ley 14/2013, de 27 de septiembre. Boletín Oficial del Estado, 233, p. 7878778882, 2013.

JEFATURA DEL ESTADO. Ley31/2015, de 9 de septiembre. Boletín Oficial del Estado, 217, p. 79824$79848,2015$.

KOSONEN, Pekka. Activation, incitations au travail et workfare dans quatre pays scandinaves, Travail et Emploi, 79. p. 1-15, 1999.

LAHERA SÁNCHEZ, Arturo. Enriquecer el factor humano. Paradigmas organizativos y trabajo en grupo, Barcelona: El Viejo Topo, 2005.

LEBEER, Guy; MARTÍNEZ, Esteban. Trabajadoras del sector de la limpieza: precariedad en el empleo, desigualdades temporalesy división sexual del trabajo, Laboreal VIII (1), p. 28-41, 2012.

LEFEBVRE, Philippe. 'Subordination et 'révolutions' du travail et du droit du travail (1776-2010), Entreprises et Histoire, 57, p. 45-78, 2009.

MARTÍN PUEBLA, Eduardo. El trabajo autónomo económicamente dependiente. Contexto europeo y régimen jurídico, Valencia, Tirant lo blanch, 2012.

MARTÍN VALVERDE, Antonio (1990): El discreto retorno al arrendamiento de servicios. In: MONTOYA, Alfredo (coord.) Cuestiones actuales del Derecho del Trabajo. Madrid: Ministerio de Trabajo y Seguridad Social, p. 209-236, 1990.

MARTÍN VALVERDE, Antonio. Trabajo asalariado y trabajo autónomo en el Derecho Comunitario europeo. In: CRUZ VILLALÓN, Jesús (ed.) Trabajo subordinado y trabajo autónomo en la delimitación de fronteras del Derecho del Trabajo. Madrid: Tecnos, p. 73-93, 1999.

MARTINVALVERDE, Antonio. Fronteras y'zonas grises' del Derecho del Trabajo en la jurisprudencia actual (1980-2001), Revista del Ministerio de Trabajo y Asuntos Sociales, 38, p. 21-50, 2002. 
MARTINVALVERDE, Antonio. Fronteras y'zonas grises' del contrato de trabajo: reseña y estudio de la jurisprudencia social (2002-2008), Revista del Ministerio de Trabajo e Inmigración, 83, p. 15-40, 2009.

MINISTERIO DE TRABAJO E INMIGRACIÓN. Real Decreto197/2009, de 23 de febrero. Boletín Oficial del Estado, 54, p. 22048-22062, 2009.

MONTOYA, Alfredo. Sobre el trabajo dependiente como categoría delimitadora del Derecho del Trabajo. In: CRUZ VILLALÓN, Jesús (ed.) Trabajo subordinado y trabajo autónomo en la delimitación de fronteras del Derecho del Trabajo, Madrid, Tecnos, p. 57-72, 1999.

MUEHLBERGER, Ulrike. Dependent Self-employment. Workers on the Border Between Employment and Self-employment. Londres: Palgrave, 2007.

OECD/EUROPEAN UNION. The Missing Entrepreneurs 2015: Policies for Self-employment and Entrepreneurship, París, OECD, 2015.

PERRAUDIN, Corinne; THĖVENOT, Nadine; VALENTIN, Julie. Subcontratación y evitación de la relación de trabajo en la industria francesa entre 1984 Y 2003, Revista Internacional del Trabajo, 132, p. $585-611,2013$.

PERULLI, Adalbert. Economically Dependent/Quasi-subordinate (Parasubordinate) Employment: Legal, Social and Economic Aspects, Bruselas, ComisiónEuropea, 2003.

RIESCO-SANZ, Alberto. Trabajo, independencia y subordinación. La regulación del trabajoautónomo en España, Revista Internacional de Sociología, 74 (1), p. 26, 2016.

ROLLE, Pierre. Travail et salariat. Bilan de la sociologie du travail, Grenoble, Presses Universitaires de Grenoble, 1988.

SERRANO PASCUAL, Amparo; MAGNUSSON, Lars . Reshaping Welfare States and Activation Regimes in Europe. Bruselas: Peter Lang, 2007.

SCHMID, Günther. Non-Standard Employment in Europe: Its Development and Consequences for the European Employment Strategy, German Policy Studies, 7(1), p. 171-210, 2011.

SUPIOT, Alain. Les nouveaux visages de la subordination, Droit Social, 2, p. 131-145, 2000.

SUPIOT, Alain (1999): Au-delà de l'emploi. Transformations du travail et devenir du droit du travail en Europe. París: Flammarion, 1999.

TERRASSE, Pascal; BARBEZIEUX, Philippe; HERODY, Camille. Rapport au Premier Ministre sur l'économie collaborative, París, La Documentation Française, 2016.

UNIÓN DE PROFESIONALES Y TRABAJADORES AUTÓNOMOS. Anuarios del Trabajo Autónomo en España, 2011-2012, Madrid, Ministerio de Empleo y Seguridad Social, 2012. 


\title{
Dados do autor
}

\begin{abstract}
Alberto Riesco-Sanz
Doctorate (PhD) / Sociology (Facultad de Ciencias Políticas y Sociología) Universidad Complutense de Madrid: Madrid, Comunidad de Madrid, ES. Profesor pesquisador seção departamental Sociología III, Universidad Complutense de Madrid: Madrid, Comunidad de Madrid, ES. Orcid: https://orcid.org/000o0002-9614-2542. E-mail: albertoriesco@ucm.es
\end{abstract}

